\title{
Estimation of the Armature Leakage Reactance using the Constant Excitation Test
}

\author{
B.T. Araujo, M.S. Han, B. Kawkabani, and E.C. Bortoni
}

\begin{abstract}
The adoption of the best available estimate for the stator Leakage reactance is the first step in several equivalent circuit of synchronous machine parameter estimation. However, there is no specific test for its direct measurement. This paper presents a simple and riskless procedure to estimate the Leakage reactance using the information obtained from the Constant Excitation Test. The method theory is described and is applied to several machines from laboratory to hydro power plants. In the absence of absolute values of the Leakage reactance, the estimates are compared to the Potier and sub-transient reactances.
\end{abstract}

Index Terms-- Synchronous machines, leakage reactance, parameter estimation.

\section{NOMENCLATURE}

$E \quad$ Induced voltage (pu)

I Load current (pu)

$I_{d} \quad$ d-Axis load current component (pu)

$P \quad$ Active power (pu)

$Q \quad$ Reactive power (pu)

$V \quad$ Terminal voltage (pu)

$V_{q} \quad$ q-Axis terminal voltage component (pu)

$V_{l} \quad$ Voltage behind the leakage reactance $(\mathrm{pu})$

$X_{a d} \quad$ Direct axis mutual reactance $(\mathrm{pu})$

$X_{d} \quad$ Direct axis synchronous reactance (pu)

$X_{q} \quad$ Quadrature axis synchronous reactance (pu)

$X_{l} \quad$ Leakage reactance $(\mathrm{pu})$

$\delta \quad$ Power angle (rad)

$\varphi \quad$ Power-factor angle (rad)

\section{INTRODUCTION}

$\Upsilon$ rear HE ARMATURE leakage may be defined as the reactance due to the difference between the total flux produced by an armature current and the flux in the airgap produced by the same armature current. There are a number of components of stator leakage. Each component represents flux paths that do not cross the airgap linking into the rotor.

The leakage inductance, or its referred reactance, is the summation of the most pronounced components, commonly referred to as slot, zigzag, belt, skew and end-winding leakage paths, and are well described in [1].

The determination of the equivalent circuit parameters of

This work was partially supported by FAPEMIG and CNPq, Brazil.

E. C. Bortoni and B.T. Araujo are with Itajubá Federal University, Itajubá MG 37500-903, Brazil (e-mail: bortoni@ieee.org; bruno_tonsic@yahoo.com. br). B. Kawkabani and M.S. Han are with the EPFL, Ecole Polytechnique Fédérale de Lausanne at the Electrical Machinery Group, CH-1015 Lausanne, Switzerland (e-mail: basile.kawkabani@epfl.ch, michel.han@epfl.ch) a synchronous machine is strongly dependent of the leakage reactance value; otherwise, an infinity number of circuits could be obtained to represent stator quantities. In fact, no matter which value of leakage reactance is adopted, with consequent variation of the equivalent circuit parameters, that the traditional parameters values will always be preserved. This issue was early pointed in [5] and formally treated in [6-7].

Therefore, the great majority of the machine modeling techniques starts with the adoption of the best available estimate for the stator leakage reactance which, in general, is considered as a given or assumed value [2-4]. This value is of utmost importance for the machine operation prediction, in both steady and transient states. Though, inappropriate specification of the leakage reactance also implies severe consequences on the saturation evaluation as the mutual reactances will vary accordingly [8].

For more than a century, the determination of the leakage reactance have fascinating researchers who work with synchronous machines modeling and parameters determination. This because the leakage reactance is neither easy to calculate nor a direct measurable quantity on the assembled machines. Therefore, many methods and tests for the leakage reactance estimation have been proposed along the years.

The Potier reactance has been largely employed as a substitute of the armature leakage reactance. It is obtained from the Potier triangle constructed with information from the open circuit, short circuit, and zero power factor characteristics [3].

Measurement of armature inductance with rotor removed is a standard method [4]. Nevertheless, it would be of difficult application in those large assembled machines. More recently, several methods have been proposed [9-12], including its approximation to the zero sequence reactance. It is worth notice that the Potier reactance has a higher value than the leakage reactance, mainly when the zero power factor test is conducted at rated voltage [13]. In addition, the leakage reactance may have a lower value than the $\mathrm{d}$ - and the q- axis sub-transient reactances, as it is an integral part of the formers. Therefore, during the comparisons, it should be kept in mind that the true leakage reactance value is smaller than the Potier and the subtransient reactances values.

\section{The CONSTANT EXCitation Test}

The Constant Excitation Test was introduced in [15] and for a synchronous machine connected to the grid operating as a generator, it consists in performing active power variation, keeping the excitation current constant.

Considering the power chart of a salient pole synchronous 


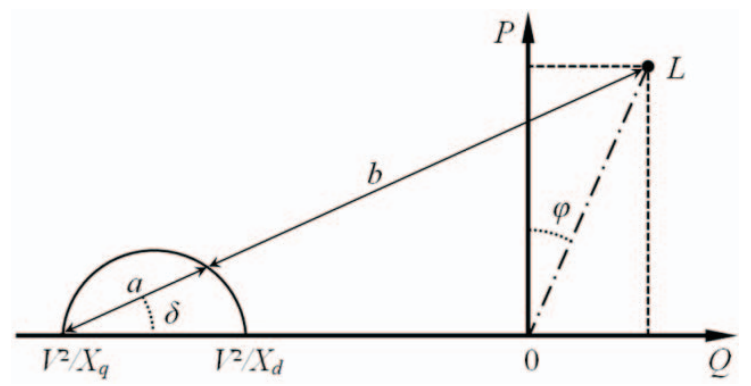

Fig. 1. Power chart of a salient pole synchronous machine.

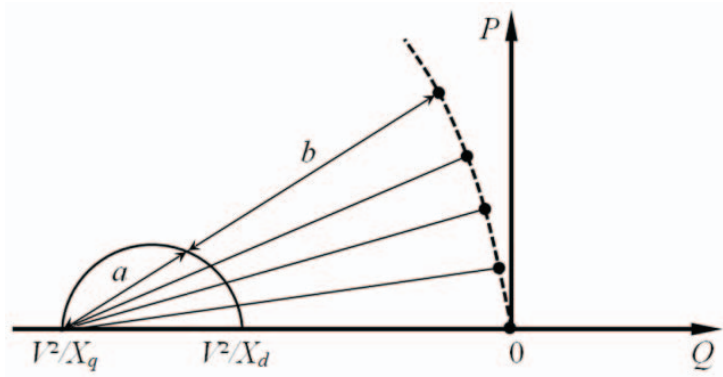

Fig. 2. Power loci for constant excitation.

machine depicted in the Fig. 1, the loading point $L$ is described by active and reactive powers, defining the powerfactor angle. The loading point is also connected to the extreme point $V^{2} / X_{q}$, defining the power angle with the reactive power axis.

The active and reactive power can be stated as a function of the length $a$, which goes from $V^{2} / X_{q}$ to the semi-circle border, and of the length $b$, which goes from the semi-circle border to the loading point $L$, as follows:

$$
\begin{gathered}
P=(a+b) \cdot \sin (\delta) \\
Q=(a+b) \cdot \cos (\delta)-\frac{V^{2}}{X_{q}}
\end{gathered}
$$

Where:

$$
\begin{gathered}
a=\left(\frac{V^{2}}{X_{q}}-\frac{V^{2}}{X_{d}}\right) \cdot \cos (\delta) \\
b=\frac{E V}{X_{d}}
\end{gathered}
$$

Moreover, if the field current is kept constant, the machine internal induced voltage will be constant. Considering the situation in which the bus is strong enough to sustain constant the terminal voltage and disregarding daxis synchronous reactance variations, the value $b$ will not vary, keeping its length constant (4).

The dashed line of Fig. 2 describes the excursion of the loading point of a generator synchronized to an infinite bus, having its active power increased by a primary mover, holding its excitation current constant. It is observed that while the active power increases, the reactive power

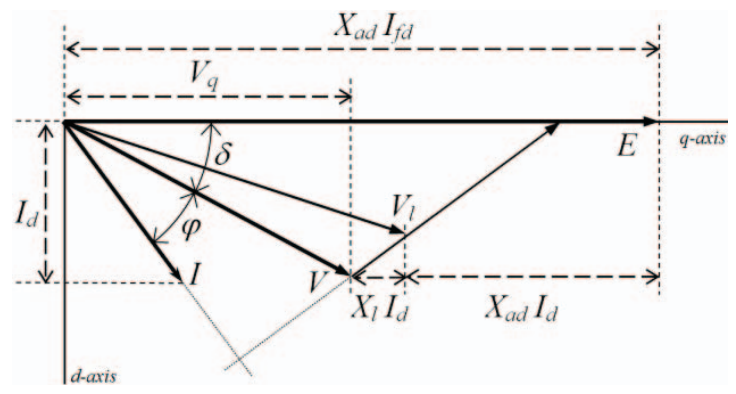

Fig. 3. Constant Excitation Test phasor diagram.

decreases, describing the complex power loci for constant field currents.

Therefore, the Constant Excitation Test is conducted as soon as the machine is connected to the power system, with null active and reactive powers, and the excitation current is that necessary to obtain rated voltage at the open circuit saturation curve. At this condition the automatic excitation mode is switched off and set to manual operation. The active power is increased in steps of about $10 \%$. In each step, voltage, active and reactive powers are registered, establishing a set of measured points.

\section{LEAKAGE REACTANCE ESTIMATION}

The determination of the leakage reactance is based on the information obtained from the Constant Excitation Test and its phasor diagram, depicted in Fig. 3. The following relationships between lengths can be obtained.

$$
X_{a d} I_{f d}=V_{q}+X_{l} I_{d}+X_{a d} I_{d}
$$

Rearranging this equation, an estimator of $X_{d}$ is given by:

$$
\hat{X}_{d}=X_{l}+\frac{V_{q}+X_{l} I_{d}}{I_{f d}-I_{d}}
$$

If reliable values $X_{d}$ and $X_{q}$ are known, power angle can be calculated, and the voltage and current components at the $d$ - and $q$ - axis as well, using (7) to (9).

$$
\begin{gathered}
\delta=\arctan \left(\frac{P}{Q+V^{2} / X_{q}}\right) \\
V_{q}=V \cdot \cos (\delta) \\
I_{d}=\frac{P}{V} \cdot \sin (\delta)+\frac{Q}{V} \cdot \cos (\delta)
\end{gathered}
$$

Therefore, equation (6) has only two incognitos, $x_{l}$ and $I_{f d}$, which are constants. The same equation can be rewritten for each loading condition measured in the Constant Excitation Test, allowing for the calculation of the $\hat{X}_{d}$ estimator.

The best estimates of $x_{l}$ and $I_{f d}$ are those whom minimizes the summation of the squares of the differences between the estimator of $\hat{X}_{d}$ and the given value of $X_{d}$. 


\section{Method APPLICATION}

The proposed method was applied to several salient pole synchronous machines of many rated sizes, from a laboratory at EPFL and from different hydro power plants. The rated values of the tested machines are summarized in Table 1.

Table 1. Rated characteristics of the tested generators.

\begin{tabular}{lcccccc}
\hline Unit & MVA & $\mathrm{kV}$ & $\mathrm{Hz}$ & $\mathrm{FP}$ & $X_{d}$ & $X_{q}$ \\
\hline Laboratory EPFL & $6.25 \cdot 10^{-3}$ & 0.380 & 50 & 0.80 & 1.210 & 0.647 \\
\hline Furnas \#2 & 160.0 & 15.0 & 60 & 0.95 & 0.859 & 0.581 \\
\hline Itaipu \#8 & 823.5 & 18.0 & 50 & 0.85 & 0.900 & 0.705 \\
\hline Itaipu \#12 & 737.0 & 18.0 & 60 & 0.95 & 0.900 & 0.690 \\
\hline Sogamoso \#2 & 324.0 & 16.5 & 60 & 0.80 & 0.953 & 0.675 \\
\hline Pehuenche \#2 & 263.0 & 13.8 & 50 & 0.95 & 1.152 & 0.703 \\
\hline
\end{tabular}

Table 2. Measurements and calculated values - EPFL Laboratory

\begin{tabular}{|c|c|c|c|c|c|c|}
\hline$P$ & 0,003 & 0,032 & 0,064 & 0,096 & 0,128 & 0,161 \\
\hline$Q$ & $-0,031$ & $-0,032$ & $-0,036$ & $-0,039$ & $-0,045$ & $-0,051$ \\
\hline$V$ & 1,005 & 1,003 & 1,005 & 1,008 & 1,009 & 1,009 \\
\hline \multicolumn{2}{|c|}{ Final values } & $X_{l}=0.052$ & & \multicolumn{2}{|c|}{$I_{f d}=0.841$} & \\
\hline
\end{tabular}

Table 3. Measurements and calculated values - Furnas \#2

\begin{tabular}{|c|c|c|c|c|c|c|}
\hline$P$ & 0.092 & 0.168 & 0.267 & 0.366 & 0.444 & 0.540 \\
\hline$Q$ & 0.014 & 0.004 & -0.005 & -0.024 & -0.043 & -0.083 \\
\hline$V$ & 1.020 & 1.020 & 1.020 & 1.020 & 1.013 & 1.007 \\
\hline \multicolumn{2}{|c|}{ Final values } & $X_{l}=0.160$ & & \multicolumn{2}{|c|}{$I_{f d}=1.482$} & \\
\hline
\end{tabular}

Table 4. Measurements and calculated values - Itaipu \#8.

\begin{tabular}{ccccccc}
\hline$P$ & 0.004 & 0.087 & 0.172 & 0.267 & 0.341 & 0.426 \\
\hline$Q$ & 0.002 & -0.003 & -0.013 & -0.030 & -0.048 & -0.072 \\
\hline$V$ & 0.981 & 0.981 & 0.979 & 0.976 & 0.972 & 0.967 \\
\hline Final values & $X_{l}=0.154$ & \multicolumn{7}{l}{$I_{f d}=1.222$} \\
\hline
\end{tabular}

Table 5. Measurements and calculated values - Itaipu \#12.

\begin{tabular}{|c|c|c|c|c|c|c|}
\hline$P$ & 0.026 & 0.102 & 0.190 & 0.291 & 0.379 & 0.471 \\
\hline$Q$ & 0.065 & 0.059 & 0.049 & 0.033 & 0.014 & -0.011 \\
\hline V & 1.031 & 1.029 & 1.027 & 1.023 & 1.021 & 1.017 \\
\hline \multicolumn{2}{|c|}{ Final values } & $X_{l}=0.116$ & & \multicolumn{2}{|c|}{$I_{f d}=1.384$} & \\
\hline
\end{tabular}

Table 6. Measurements and calculated values - Sogamoso \#2.

\begin{tabular}{llllll}
\hline$P$ & 0.022 & 0.156 & 0.309 & 0.461 & 0.612 \\
\hline$Q$ & 0.130 & 0.120 & 0.096 & 0.054 & -0.002 \\
\hline$V$ & 1.026 & 1.024 & 1.019 & 1.013 & 1.001 \\
\hline \multicolumn{2}{l}{ Final values } & $X_{l}=0.118$ & & $I_{f d}=1.370$ \\
\hline
\end{tabular}

Table 7. Measurements and calculated values - Pehuenche \#2.

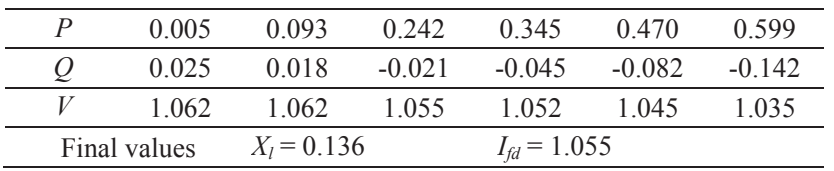

Measurements were taken as soon as the machines were synchronized to the power system. Keeping the excitation current constant the units were loaded, voltage and active and reactive powers were recorded.

A spreadsheet was developed for the $\mathrm{d}$ - and q- axis quantities calculation, and for the $X_{l}$ evaluation from the several measurements, using a first guess of $X_{l}$ and $I_{f d}$ based on their typical per unit values. A solver feature was employed to find the best estimates of $X_{l}$ and $I_{f d}$ that minimizes the sum of the squared differences between the calculated and the given value of $X_{d}$.

Per unit measurements and the results from the application of the proposed methodology are summarized in the tables 2 to 7 . For results evaluation purposes, the obtained leakage reactances were compared to the available values of reactance of Potier or to the direct axis subtransient reactance.

\section{A. EPFL laboratory machine}

The laboratory machine depicted in Fig. 4 was tested employing the proposed technique. On the other hand, this machine was extensively studied and had its parameters calculated using several standard techniques [14], consisting on a excellent base of comparison. Table 2 presents the measurements of active and reactive powers and voltage according the Constant Excitation Test.

The obtained $X_{l}$ is $0.057 \mathrm{pu}$, which agrees with the 0.06 pu Potier reactance. This leakage reactance is also lower than the minimum sub-transient reactance value of $0.13 \mathrm{pu}$. Appendix I presents machine testing and reactances calculations.

\section{B. Furnas Hydro Power Plant}

Furnas is a hydro power plant has eight 160 MVA units. Measurements made in unit \#2 and result are described in Table 3. The calculated leakage reactance is $0.16 \mathrm{pu}$. For this machine, the reactance of Potier is $0.18 \mathrm{pu}$ and the directaxis sub-transient reactance is $0.20 \mathrm{pu}$. Therefore, the obtained result seems to be in accordance of the existent information.

\section{Itaipu Hydro Power Plant}

Itaipu is a $14,000 \mathrm{MW}$ bi-national Brazil-Paraguay hydro power plant. Half of the 20 existent units generates voltage at $50 \mathrm{~Hz}$ to supply Paraguay, the other half generates at 60 $\mathrm{Hz}$ to supply Brazil. The Constant Excitation Test was applied to both types of machines.

Table 4 presents the measurements made in the unit \#8, $50 \mathrm{~Hz}$, and table 5 presents the measurements made in the unit \#12, $60 \mathrm{~Hz}$. The obtained values of $X_{l}$ were 0.154 pu for the $50 \mathrm{~Hz}$ machine and $0.116 \mathrm{pu}$ for the $60 \mathrm{~Hz}$ machine. The $\mathrm{d}$-axis sub-transient reactance values are $0.25 \mathrm{pu}$ and 0.24 pu, respectively.

\section{Sogamoso Hydro Power Plant}

Sogamoso is hydro power plant in Colombia and the underground powerhouse accounts with three units totalizing 820 MW. The Constant Excitation Method was applied to 
the unit \#2 and the obtained measurements are presented in Table 6. The same table shows the resultant leakage reactance of $0.118 \mathrm{pu}$. The given values of the leakage reactance and of the d-axis sub-transient reactance are 0.13 and 0.246 respectively.

\section{E. Pehuenche Hydro Power Plant}

The Pehuenche hydro power plant is located in Chile. Measurements and calculations are described in Table 7. The obtained $X_{l}$ is $0.136 \mathrm{pu}$, which is in consonance with the given values of the Potier reactance and of the d-axis subtransient reactance are 0.16 and 0.215 respectively.

\section{CONCLUSIONS}

This paper presented a novel methodology to estimate the armature leakage reactance of a synchronous machine, using the Constant Excitation Test and simple calculations over the measured data. The method was applied to different salient pole generators achieving very good results. The obtained leakage reactances were simply compared to values declared by manufacturers, obtained from standard methods, or to the $\mathrm{d}$-axis sub-transient reactance, rather than specifying any error metric. This was done because, due to the small values of the leakage reactance, the percentage errors seem to be larger even for the minor differences.

It should be reinforced that the test is simple to apply and can be applied to a machine under operation with virtually no-cost and no-risk of damage. The method is suitable for medium and large sized power machines already installed or those constructed in the field, rather than for the prototypes or laboratory machines. For the large machines, the armature resistance can be neglected and the obtained leakage reactance is useful to evaluate design assumptions, to compare with manufacturer information, or simply to retrieve lost information.

\section{ACKNOWLEDGMENTS}

The authors appreciate FAPEMIG, CNPq, and INERGE for support to conduct research. Special thanks to R.T. Siniscalchi, M.A.S. Mauro, and to ABB field service engineers that have sent measurements from tested units.

\section{REFERENCES}

[1] T. A. Lipo. Analysis of Synchronous Machines, Second Edition. June 25,2012

[2] IEEE Std. 1110. IEEE Guide for Synchronous Generator Modeling Practices and Applications in Power System Stability Analyses. IEEE Power and Energy Society, New York, 2002.

[3] IEEE Std. 115. IEEE Guide for Test Procedures for Synchronous Machines Part II-Test Procedures and Parameter Determination for Dynamic Analysis. IEEE Power and Energy Society, New York, 2009.

[4] IEC 60034-4. Rotating electrical machines - Part 4: Methods for determining synchronous machine quantities from tests. Edition 3.0 International Electrotechnical Commission, Genève, Switzerland, 2008 .

[5] I.M. Canay. Causes of Discrepancies on Calculation of Rotor Quantities and Exact Equivalent Diagrams of the Synchronous Machine. IEEE Trans. on PAS-88(7), 1969, pp. 1114-1120.

[6] J.L. Kirtley Jr. On Turbine-Generator Rotor Equivalent Circuits. IEEE Trans. PWRS-9(1), Feb. 1994, pp. 262-271.

[7] I. Kamwa, P. Viarouge. On Equivalent Circuit Structures for
Empirical Modeling of Turbine-Generators. IEEE Trans. on EC-9(3), Sept.1994, pp. 579-592.

[8] D.C. Aliprantis, S.D. Sudhoff, B.T. Kuhn. A Synchronous Machine Model With Saturation and Arbitrary Rotor Network Representation. IEEE Trans. on EC-20(3), Sept. 2005, pp. 584-594.

[9] D.C. Aliprantis, S.D. Sudhoff, B.T. Kuhn. Experimental Characterization Procedure for a Synchronous Machine Model With Saturation and Arbitrary Rotor Network Representation. IEEE Trans. on EC-20(3), Sept. 2005, pp. 595-603.

[10] F.P. de Mello, L.N. Hannett, J.R. Willis. Determination of Synchronous Machine Stator and Field Leakage Inductances from Standstill Frequency Response Tests. IEEE Trans. on PWRS-3(4), Nov. 1988, pp. 1625-1632.

[11] A. El-Serafi, J. Wu. A new method for determining the armature leakage reactance of synchronous machines. IEEE Trans. on EC-6(1), Mar. 1991, pp. 120-125.

[12] G. Lossa, F. Vallée, Z. Grève, M.Delhaye. An original method for measuring the stator leakage reactance of synchronous machines. 2015 IEEE International Conference on Industrial Technology (ICIT), 1719 March 2015, Seville, Spain, pp. 617-622.

[13] T. Hikihara, T. Okajima. Physical meaning of the Potier triangle based on the analysis of magnetic flux saturation. IEEE Transactions on Magnetics, Vol. 24(5), Sept. 1988, pp. 2186-2193.

[14] J. Huang, K.A. Corzine, M. Belkhayat. Online Synchronous Machine Parameter Extraction From Small-Signal Injection Techniques. IEEE Trans. on EC-24(1), Mar. 2009, pp. 43-51.

[15] E. C. Bortoni, B.T. Araujo, J.A. Jardini. Estimation of Quadrature Axis Synchronous Reactance Using the Constant Excitation Test. IEEE Power and Energy Technology Systems Journal, Vol. 1, No 1, 2016, pp. 1-8.

[16] M.S. Han. Feasibility of monitoring application based on real-time simulation in SIMSEN. Ph.D. dissertation n 6814, EPFL, 2015.

\section{APPENDIX \\ LABORATORY MACHINE PARAMETERS ESTIMATION}

Potier reactance and sub-transient reactances were determined for the laboratory machine. Open circuit, short circuit, and zero power factor tests were carried out [4] and the results are shown in Figs. 5-a, 5-b, and 5-c, respectively. Fig. 5-d shows details to obtain the voltage across the Potier reactance, which was found $0.06 \mathrm{pu}$.

Sub-transient reactances were measured using the applied voltage test with the rotor in an arbitrary position [5]. In this test the synchronous machine rotates at a very low speed with the short-circuited rotor circuit.

Two phases are supplied with a single-phase AC voltage source at rated frequency and the voltage necessary to induce a current between 0.2 and $0.7 \mathrm{pu}$. Armature voltage and current, and field current are measured.

The axis positions are known with the current induced in the rotor circuit as seen in Fig 6. The d-axis corresponds to the instant related to the maximum field current, whereas the quadrature axis is assigned to the minimum amplitude. For each case, the sub-transient reactance is calculated as:

$$
X^{\prime \prime}=\sqrt{\left(\frac{V}{2 I}\right)^{2}-\left(\frac{P}{2 I^{2}}\right)^{2}}
$$

The obtained values are $0.13 \mathrm{pu}$ and $0.22 \mathrm{pu}$, for $X^{\prime \prime}{ }_{q}$ and $X^{\prime \prime}{ }_{d}$, respectively. 


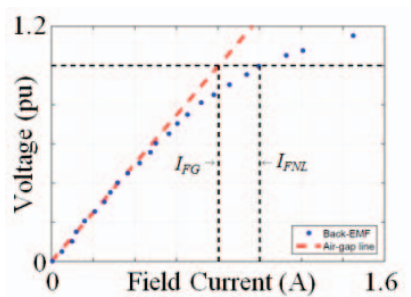

(a)

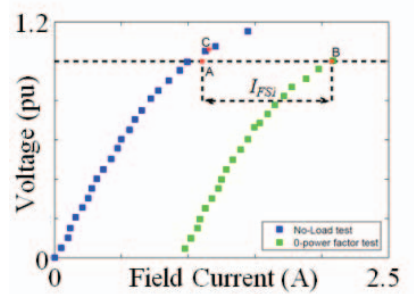

(c)

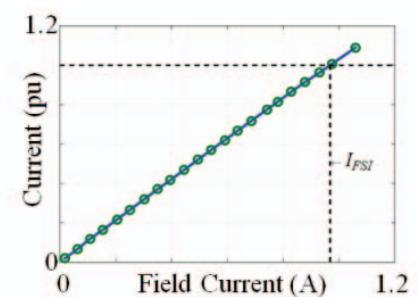

(b)

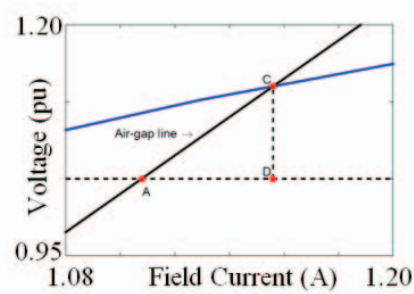

(d)
Fig. 5. Tests for Potier reactance determination.
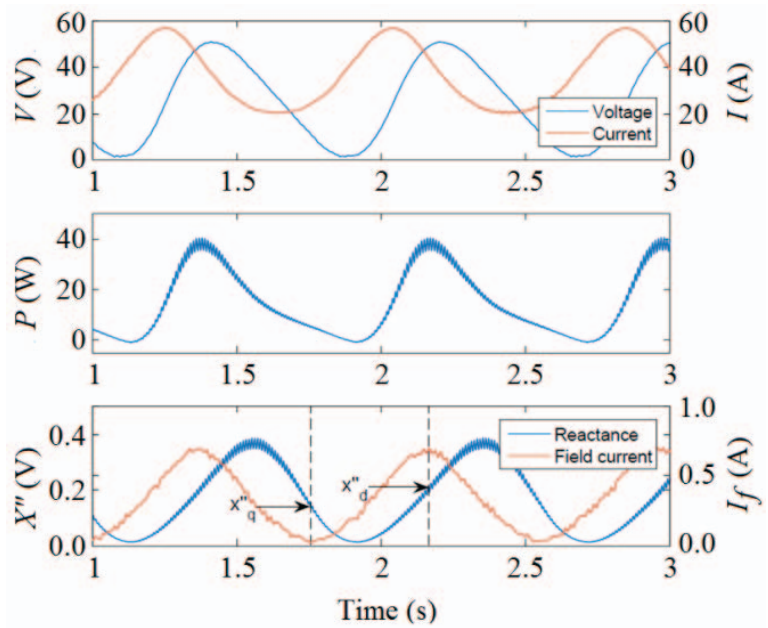

Fig. 6. Oscillation of RMS values according to the rotor position.

\section{BIOGRAPHIES}

Bruno Tonsic de Araujo (S’ 2014) was born in São José dos Campos, Brazil, on March 14, 1984. He was member of the Tutorial Education Program as undergraduate student and received his Electrical Engineering degree from UNIFEI in 2008. Currently he works as a project engineer in ABB Brazil, at the excitation systems department, and is also M. Sc. student at UNIFEI. His interests include parameter identification, synchronous machines modeling, system stability, and power generation.

Michel Sangkyu Han (S' 2015) was born in Geneva, Switzerland, on February 26, 1986. He received his B.Sc., M.Sc., and Ph.D in Electrical Engineering from Swiss Institute of Technology at Lausanne, in 2009, 2011 and 2015, respectively. He was member of the Student association in electrical engineering and a past president of the committee. His interests include real time simulation, model-based monitoring, electromechanical energy conversion, transients of electrical machines, parameters identification, and power generation.

Basile Kawkabani (SM'11) received his master degree in 1978 from SUPELEC, Ecole Supérieure d'Electricité in Paris France, and his PhD degree in 1984 in Electrical Engineering from the Swiss Federal Institute of Technology in Lausanne (EPFL). From 1992 to 2010, he was lecturer and research associate at the EPFL Electrical Machinery Laboratory. He is currently a senior scientist in STI Scientists Group (Electrical Machinery). His research interests are related to the modeling and study of dynamical behavior of middle-sized and large electrical machines, electrical networks and adjustable speed drives, and to the numerical analysis including $2 \mathrm{D}$ and $3 \mathrm{D}$ Finite Element computations (FEM). Basile is a senior member of the IEEE, member of the steering committee of the International Conference on Electrical Machines (ICEM), and reviewer for international journals and conferences.

Edson da Costa Bortoni (S'94-M'96-SM'05) was born in Maringá, Brazil, on December 1, 1966. He received the Electrical Engineering degree from Itajubá Federal University (UNIFEI), Itajubá, Brazil, in 1990; the M.Sc. degree in energy systems planning from the University of Campinas, Campinas, Brazil, in 1993; the D.Sc. degree in power systems from the Polytechnic School of the University of São Paulo (USP), São Paulo, Brazil, in 1998; and the Academia Scholar degree (Habilitation) from USP, São Carlos, Brazil, in 2012. He was a Visiting Professor with Amazon University, Manaus, Brazil, an Adjunct Professor at São Paulo State University, Guaratinguetá, Brazil, and a Visiting Scholar at École Polytechnique Fédérale de Lausanne, Switzerland, in 2015. He is currently a Professor at UNIFEI. His research interests include electrical machines, instrumentation, power generation, smart grids, and energy systems. Dr. Bortoni was elected as a 2014-2015 Star Reviewer of the IEEE Transactions ON ENERGY CONVERSION. He is a Fellow Member of the Instrument Society of Automation. 